\title{
Espécies de Neomarica Sprague (Iridaceae): potencial ornamental e cultivo
}

\author{
LINDOLPHO CAPELLARI JÚNIOR
}

\section{INTRODUÇÃO}

Iridaceae Juss. é uma família de monocotiledôneas com 70 gêneros e cerca de 1.750 espécies (GOLDBLATT et al., 1998) de ampla distribuição geográfica, especialmente no Sul da África e no continente americano (HEYWOOD, 1979).

Segundo GOLDBLATT (1990), Iridaceae é composta por quatro subfamílias, e destas, apenas Iridoideae tem representantes no continente americano. Essa subfamília é formada por quatro tribos, duas das quais são exclusivamente neotropicais: Mariceae e Tigridieae. A primeira, com a grande maioria das espécies neotropicais, porém com alguns representantes pantropicais (Sisyrinchieae) e a segunda com ampla distribuição pantropical, mas com alguns representantes na América do Norte (Irideae), à qual pertence Iris L., o gênero típico da família (DAHLGREN et al., 1985).

A combinação dos caracteres - ovário ínfero e três estames - distingue Iridaceae das demais famílias afins, da ordem Liliales (Liliaceae e Amaryllidaceae, entre outras).

Se as espécies herbáceas nativas antes eram desconhecidas ou pouco conhecidas, atualmente começaram a aparecer em obras bibliográficas de divulgação, como em LORENZI \& MOREIRA (1995). Um bom guia para um maior conhecimento das iridáceas no mundo todo, incluindo outros gêneros brasileiros potencialmente ornamentais, foi apresentado por INNES (1985).

No Brasil, ocorrem treze gêneros e grande número de espécies, com uma taxonomia complexa. Dentre os diversos gêneros nativos com representantes ornamentais, destaca-se Neomarica Sprague.

\section{O GÊNERO NEOMARICA SPRAGUE}

Neomarica é um gênero composto por vinte espécies que se distribuem ao longo da costa oriental do continente americano, do sudeste mexicano até o Uruguai. Algumas espécies são típicas dos campos de Minas Gerais, São Paulo, Paraná, Paraguai e nordeste argentino (CAPELLARI JR., 2000).

As espécies desse gênero foram descritas como Iris L., Moraea Mill., Galathea Salisb. e Marica Ker Gawl.; foram sinonimizadas em Cipura Aubl., Cypella Herb. (CAPELLARI JR., 2000). SPRAGUE (1928), ao rever a sistemática desse grupo, propôs o novo nome genérico Neomarica, visto que os anteriores não obedeciam às regras da nomenclatura botânica ou estavam sendo usados indevidamente.

RAVENNA (1978) propôs a inclusão das espécies Neomarica em três seções distintas de Trimezia Salisb. ex Herb., mas essa proposta foi refutada por iridólogos que trabalharam com este grupo (CHUKR, 1997 e 1998; CAPELLARI JR., 2000). O nome Neomarica foi revalidado por CHUKR \& GIULIETTI (1998).

A maioria das espécies de Neomarica (denominadas "neomáricas", no presente trabalho) é típica da Mata Atlântica, desde áreas próximas às dunas até o topo das matas costeiras.

A folhagem em leque, ereta ou arqueada para um dos lados, já torna esta planta um exemplar ornamental. Aliás, essas plantas formam touceiras graciosas com belas tonalidades de verde.

A floração ocorre no período primavera-verão, podendo estender-se um pouco mais, de acordo com o fornecimento de condições ótimas de cultivo. A inflorescência básica tem a forma de um cartucho

\footnotetext{
${ }^{1}$ Departamento de Ciências Biológicas - ESALQ/USP, Caixa Postal 09, 13418-900, Piracicaba (SP). E-mail: 1capella@carpa.ciagri.usp.br
} 
(morfologicamente, é um ripídio) e geralmente em cada haste floral (escapo), há um conjunto desses "cartuchos" que produz diversas flores que desabrocham em seqüência centrípeta.

As flores são vistosas e efêmeras, actinomorfas (simetria radial) com o perianto (cálice e corola) petalóide, isto é, tanto as sépalas quanto as pétalas são coloridas. Esses elementos, tecnicamente denominados tépalas (externas e internas), possuem a região basal tigradas de vinho ou ferrugem; as tépalas externas são mais ou menos elípticas, brancas, amarelas, azuis, violeta ou magentas; as internas são sigmóides com ornamentações tigradas de azul cobalto ou violeta e duas manchas amarelas a laranja, pequenas e redondas na região central. Essas características morfológicas são básicas para todas as espécies do gênero.

Os frutos são como os da grande maioria das iridáceas e similares aos de certas liliáceas (Hemerocallis, por exemplo). Na única espécie de Neomarica que não é nativa do Brasil, os frutos, bem como as sementes, são vermelhos ou alaranjados, e, nas demais espécies, são marrons.

\section{PROPAGAÇÃO}

A propagação de espécimes de neomáricas pode ser realizada de quatro maneiras: removendo-se da terra uma pequena porção de seu rizoma (que contenha ao menos uma gema), coletando-se propágulos aéreos ("brotos" que surgem nas inflorescências), separando-se mudas de touceiras e, finalmente, coletando-se sementes.

Na divisão de touceiras (prática bastante empregada), a planta-mãe é arrancada e separada em diversas touceiras menores; na estaquia de rizomas a parte aérea é eliminada e o sistema subterrâneo contendo raízes e rizomas é cortado em diversos pedaços; o plantio de propágulos aéreos origina plantas adultas em pouco tempo. Sua semeadura deve ser feita preferencialmente em solo arenoso.

Qualquer um desses métodos, aliás bem conhecidos na floricultura, pode ser aplicado com sucesso.

\section{CULTIVO}

As neomáricas preferem solos arenosos, ricos em matéria orgânica e com boa drenagem. Solos compactados, especialmente argilosos e com má drenagem acarretarão, em plantas menores, floração reduzida ou com problemas fitossanitários.
Apesar de apreciarem muito a luminosidade, desenvolvem-se melhor à meia-sombra, visto que, a pleno sol, suas folhas tornam-se amarelas e as flores, mais pálidas, murcham rapidamente.

De modo geral, necessitam água em abundância (salvo as espécies campestres), a qual deve ser fornecida no final da tarde. Suas flores são tão delicadas que a irrigação por aspersão durante o dia, além de ser uma prática inadequada (as gotículas sobre folhas e flores atuam como lentes convergentes de calor), danifica bastante a morfologia floral.

Essas plantas não necessitam de cuidados especiais, porém folhas velhas ou danificadas e hastes florais (escapos), cujos propágulos e frutos já se desenvolveram, devem ser removidos.

Quando as touceiras estiverem sem espaço, isto é, quando se percebe que há uma superpopulação, elas devem ser arrancadas e parte replantada. É recomendável que as folhas sejam cortadas no replantio e que tal prática seja realizada no outono, após a formação de sementes.

\section{UTILIZAÇÃO}

As neomáricas podem ser usadas como forração ou maciços e ser cultivadas sob árvores (são típicas de sub-bosque), ou ao longo de caminhos e em bordas de espelhos-d'água, onde ficam bastante graciosas. Adaptam-se bem em jardineiras e vasos.

A disposição eqüitante (similar a um grande leque) das folhas é também um caráter ornamental, além da beleza das flores. Outra característica interessante para o paisagismo é a presença de rizomas que auxiliam a contenção de solos em terrenos com declividade acentuada.

\subsection{Espécies já cultivadas e/ou comercializadas}

Algumas espécies já são cultivadas em jardins residenciais e públicos, podendo ser encontradas no comércio com os nomes de "pseudo-iris", "íris" (um nome errôneo) ou "lírio-na-folha" (nome mais empregado no Nordeste). A sugestão, porém, é que o nome comercial ou agronômico seja "neomárica", acrescido de um adjetivo de acordo com cada espécie (CAPELLARI JR., 2000).

Dentre as mais conhecidas (Figura 1), destacam-se Neomarica sabini (Lindl.) Chukr com flores violeta (às vezes pintalgadas de violeta mais escuro) em plantas de 0,5-1m, com folhas decumbentes; 


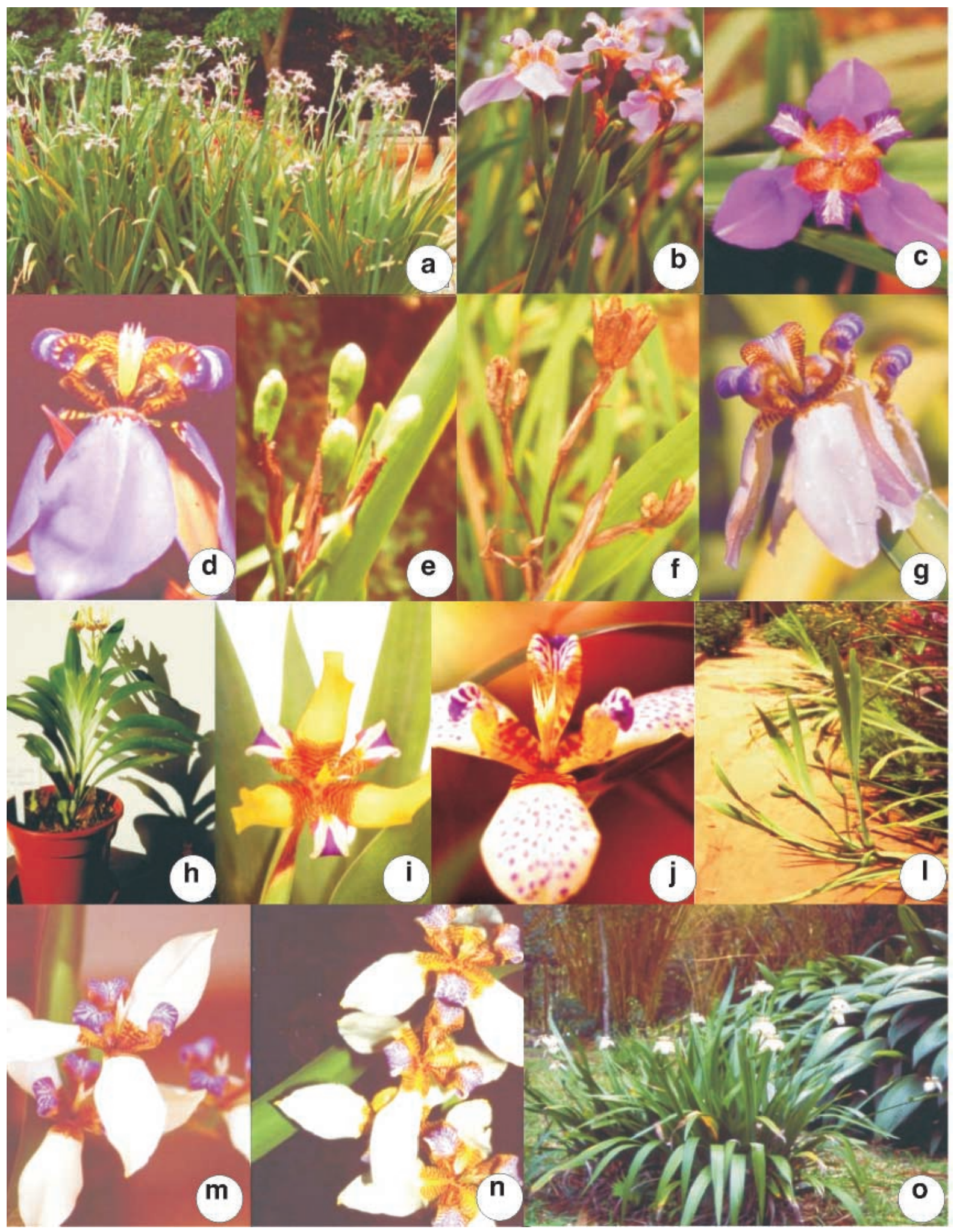

Figura 1. a. Neomarica caerulea (aspecto da planta); b. N. caerulea (flores); c. N. eximia (flor); d. $N$. sabini (flor); e. N. caerulea (frutos jovens); f. N. caerulea (frutos maduros); g. N. fluminensis (flores); h. N. sylvestris (aspecto da planta); i. N. sylvestris (flor); j. N. guttata (flor); l. N. caerulea (propágulos aéreos); m. $N$. candida (flor); n. N. northiana (flores); o. N. northiana (aspecto da planta) 
N. caerulea (Ker Gawl.) Sprague cujas flores vão do azul celeste ao violeta, em plantas com $1,5 \mathrm{~m}$ e folhas eretas a ligeiramente decumbentes; $N$. eximia (Ravenna) Capellari Jr. com flores magentas, folhagem bastante decumbente e graciosa, em indivíduos de 1-1,5m; N. fluminensis (Ravenna) Chukr com flores lilases, plantas de $50-80 \mathrm{~cm}$ e folhagem extremamente decumbente, se cultivada ao sol, porém mais ereta (e mais alta), se cultivada à sombra; $N$. candida (Hassl.) Sprague, com flores brancas, folhagem em leque bem aberto e decumbente, de cerca de $50 \mathrm{~cm}$ e, finalmente, $N$. northiana (Schneev.) Sprague, com as mesmas características de $N$. fluminensis, à exceção das flores, similares às de $N$. candida.

Todas são nativas da Mata Atlântica, variando a sua distribuição geográfica entre os estados da Bahia e Santa Catarina. A Neomarica candida e a $N$. caerulea ocorrem também no Paraguai e na Argentina (nordeste).

As espécies acima citadas foram cultivadas no Departamento de Ciências Biológicas da ESALQ/ USP.

Em países centro-americanos é cultivada a Neomarica variegata (M.Martens \& Galeotti) Henrich \& Goldblatt, nativa das florestas da Venezuela, ao sudeste do México.

\subsection{Espécies desconhecidas em paisagismo}

Um maior número de espécies, entretanto, é desconhecido como planta cultivada. Entre as espécies de flores azuladas estão: Neomarica rigida (Ravenna) Capellari Jr. (*) cujas flores são grandes e violeta, com folhagem ereta de $50-80 \mathrm{~cm}$, nativa nos campos naturais (São Paulo e Paraná), e N. glauca (Seub. ex. Klatt) Sprague com pequenas flores azuis em plantas de pequeno porte $(40-60 \mathrm{~cm})$, a qual cresce em áreas montanhosas (Rio de Janeiro e Minas Gerais).

As espécies de flores amareladas ainda não cultivadas são: Neomarica humilis (Klatt) Capellari Jr. e $N$. lutea (Herb.) Sprague, cuja distinção é difícil (arranjo da inflorescência e estiletes), apresentando ambas flores amarelo-claros, folhagem decumbente e cerca de 0,8-1m de altura, típicas da Mata Atlântica (diversos estados brasileiros, especialmente Rio de Janeiro ); N. longifolia (Link \& Otto) Sprague que apresenta inflorescências com muitas flores pequenas, folhagem mais delicada (fina e decumbente) em plantas de $1 \mathrm{~m}$ aproximadamente, típica dos litorais paulistas e cariocas e, finalmente, $N$. portosecurensis (Ravenna) Chukr com folhagens mais ou menos si- nuosa, cerca de $80 \mathrm{~cm}$ de altura, originária do litoral da Bahia (e em alguns outros estados).

As espécies brasileiras com flores brancas ainda não exploradas pelo paisagismo são: Neomarica imbricata (Hand-Mazz.) Sprague(*), cuja característica é a folhagem verde-escuro (verde-musgo), ligeiramente decumbente, em plantas de cerca de $80 \mathrm{~cm}$, típica de sub-bosques de florestas semideciduais e que vem sendo ameaçada graças à degradação de seu habitat e N. gracilis (Herb.) Sprague que produz flores pequenas em inflorescências ramificadas e graciosas, touceiras com folhas finas em leques bem delicados de até $1 \mathrm{~m}$ de altura, sendo nativa nas restingas (São Paulo e Rio de Janeiro).

Neomarica sylvestris (Vell.) Chukr(*) produz as menores e mais delicadas plantas $(20-50 \mathrm{~cm})$, com um pequeno caule aéreo ereto (semelhante ao de uma comelinácea), com folhas caídas para um dos lados e flores amarelo-creme ou violáceas. É típica de áreas muito úmidas da Mata Atlântica (Espírito Santo a São Paulo), e poderia ser cultivada em jardins de inverno, porque não suporta baixa umidade relativa do ar nem luz solar incidente.

Como espécies ainda pouco conhecidas e recentemente apresentadas estão Neomarica pulchella Capellari Jr.(*) e N. guttata Capellari Jr.(*), provenientes da Mata Atlântica (Espírito Santo e São Paulo respectivamente) que se adaptaram bem às condições de cultivo, vindo a florescer abundantemente. $N$. pulchella possui flores amarelas com uma faixa branca (nas tépalas externas) em plantas de $50 \mathrm{~cm}$ aproximadamente, com folhas largas em leque bem aberto e decumbente, e $N$. guttata que tem tépalas externas alvas pintalgadas de violeta (o que a torna muito ornamental), além das plantas em leque aberto e folhagem caída para um dos lados, formando plantas de cerca de $50-70 \mathrm{~cm}$.

As espécies assinaladas com asterisco foram cultivadas no Departamento de Ciências Biológicas da ESALQ/USP (Piracicaba/SP) e adaptaram-se bem em ripado, vindo a florescer.

\subsection{Espécies que necessitam estudos de domesticação}

Nas montanhas de Minas Gerais pode ser encontrada Neomarica rupestris (Ravenna) Chukr com folhas rígidas, eretas e belíssimas flores violeta. Apesar de ser cultivada com sucesso por moradores da Serra do Cipó, espécimes trazidos para cultivo (ESALQ/USP), com solo coletado no próprio habitat, 
vegetaram bem durante dois anos e pereceram, sem florescer. Esta espécie merece um estudo agronômico de "domesticação".

Neomarica paradoxa (Ravenna) Chukr é malconhecida; nada se pode afirmar sobre seu potencial ornamental ou mesmo se ela se adapta a condições de cultivo. Também no estudo taxonômico desse gênero, pode-se observar que a espécie está muito mal representada nas coleções dos herbários.

\section{CONSIDERAÇÕES FINAIS}

O gênero Neomarica, como tantos outros de plantas herbáceas tropicais, apresenta um potencial ornamental enorme e ainda pouco explorado. O cultivo de plantas nativas nos jardins brasileiros é uma forma de preservar espécies que estão com seus habitats ameaçados.

A conciliação entre espécies exóticas e nativas é perfeitamente possível e, se bem planejada, formará jardins com flores durante o ano todo.

\section{REFERÊNCIAS BIBLIOGRÁFICAS}

CAPELLARI JR., L.Revisão taxonômica do gênero Neomarica Sprague (Tribo Mariceae, Subfamília Iridoideae, Iridaceae). Campinas: Instituto de Biologia, Universidade Estadual de Campinas, 2000. 300p. Tese de Doutorado.

CHUKR, N.S. A família Iridaceae na Serra do Cipó, Minas Gerais, Brasil. São Paulo: Instituto de Biociências da Universidade de São Paulo, 1998. 275p. Dissertação de Mestrado.

CHUKR, N.S.Revisão taxonômica dos gêneros Pseudotrimezia Foster e Trimezia Salisb. ex Herb. para o Brasil. Iridaceae. Mariceae. São Paulo: Instituto de Biociências da Universidade de São Paulo, São Paulo, 1997. 323p. Tese de doutorado.

CHUKR, N.S. \& GIULIETTI, A.M. Revalidação de Neomarica Sprague (Iridaceae) e novas combinações para este gênero. In: CONGRESSO BRASILEIRO DE BOTÂNICA, 49., Salvador, 1998. Anais... Salvador, 1998. p.77.

DAHLGREN, R.M.T.; CLIFFORD, M.T. \& YEO, P.F. 1985. The families of the monocotyledons - structure, evolution and taxonomy. Springer-Verlag: Berlin. $520 \mathrm{p}$.

GOLDBLATT, P. Phylogeny and classification of Iridaceae. Ann. Mo. Bot. Gdn., v.77, p.607-627. 1990.

GOLDBLATT, P.; MANNJNG, J.C. \& RUDALL, P. The families and genera of vascular plants. SpringerVerlag: Viena, 1998. p.295-333.

HEYWOOD, V.H. Flowering plants of the world. Oxford: Oxford University Press, 1979. p.311-312.

INNES, C. The world of Iridaceae - a comprehensive record. Holly Gate International Ltd. Ashinton, Sussex RH20 3BA, England. 1985.

LORENZI, H. \& MOREIRA, H. Plantas ornamentais do Brasil - arbustivas, herbáceas e trepadeiras. Ed. Plantarum Ltda. Nova Odessa, São Paulo, 1995. p.387405.

RAVENNA, P. New species and miscellaneous notes in the genus Trimezia (Iridaceae) - II. Onira, 1988. v.1. n.1, p.1-15.

SPRAGUE, T.A. Marica and Neomarica. Bull. Misc. Inform., p.78-281. 1928. 